\title{
Study of Mental Health Status of the Family Members of Disappeared Persons of Kashmir
}

\author{
Suhail Ahmad Bhat ${ }^{1}$, Dr. Shawkat Ahmad Shah ${ }^{2}$
}

\section{ABSTRACT}

While trying to portray the picture of mayhem and woes of family members of those who disappeared, it fails to fully convey the agony of the survivors. Their emotions are so intense that a normal person can hardly help his emotional shutters. Even a single experience with a family member of a disappeared person makes one to ponder that how unbearable it is to be a mother, father, wife or son of disappeared person. Their search for the disappeared family member along with hardships of daily life, social stigmas, economic and educational needs have left their mental health par below average level. One finds the words of depression, stress, anxiety, sleeplessness and melancholy in their everyday lexicon. With such a despondent picture of family members of disappeared persons in mind, the present attempt was made to study the nature of their mental health. To achieve this objective, data was collected from 217 family members of disappeared persons of Kashmir. The frequency method and t-test were used to obtain the results. The results of the study showed that majority of the family members scored high in negative dimensions of mental health namely, anxiety, depression and loss of behavioral and emotional control and low in positive dimensions of mental health namely, general positive affect, emotional ties and life satisfaction. A significant difference was found in mental health on the basis of gender, age and family type.

Keywords: Disappearance, Mental disorders, Depression, Life Satisfaction.

Disappearance is a worldwide problem. Over the last few decades, the World has been shocked by accounts of tens of thousands of people who are known to have disappeared due to one or another reason. Forced disappearances have an effect on the individual, his/her family and the community as a whole. The problems that family members of disappeared persons face are complex and can be overwhelming. Besides the uncertainty about the fate of their relatives, they usually have to cope with economic, social, legal and mental problems as well. Many relatives have searched in vain for their loved ones, year after year. We know mothers of disappeared children who, after almost thirty years, are still hoping for their missing child to appear. It is normal for relatives to have difficulties in accepting the death of a disappeared family member. In many cases, family members of disappeared persons suffer from symptoms of complicated

\footnotetext{
${ }^{1}$ Research Scholar Department of Psychology, University of Kashmir

${ }^{2}$ Associate Professor, Department of Psychology, University of Kashmir *Corresponding Author

(C) 2015 I S Bhat, S Shah; licensee IJIP. This is an Open Access Research distributed under the terms of the Creative Commons Attribution License (http://creativecommons.org/licenses/by/2.0), which permits unrestricted use, distribution, and reproduction in any Medium, provided the original work is properly cited.
} 


\section{Study of Mental Health Status of the Family Members of Disappeared Persons of Kashmir}

grief, such as intrusive images or severe emotional attacks, or from denial of the effects of loss, depression, anxiety, guilt, pessimism, Post traumatic stress disorder, dissatisfaction with life, lack of emotional control, unhealthy coping strategies, etc. As a result, they often find it hard to cope with necessary activities at work and at home (Horowitz, 1997). Moreover, the psychological effects of political disappearance and assassination on surviving child family members has been found so severe that these children remain symptomatic for many years and mostly suffer from trauma, melancholy, anxiety and truculent feelings (Munczek \& Tuber, 1998). Numerous interviews and reports regarding the impact of forced disappearance on the physical and psychological health of family members have surfaced constellations of stress, trauma and anxiety related symptoms. It is also observed that the prevalence of post traumatic stress disorder is two times more in families of the disappeared persons as compared to those who have not lost their near ones during the past ten years. At the same time, the atmosphere of fear and isolation experienced by families of the disappeared is the causative factor in the prolonging the stress-related disorders years after the traumatic event (Gregory \& Quirk, 1994). Moreover, it has been found that the children of disappeared persons living in the hope of return of their parent(s) suffer from extreme depression and melancholy (Hasanovic, Sinanovic \& Pavlovic, 2002). At the same in a society dominated by organized violence, serious mistrust is created between people. Neighbors, classmates and other community members sometimes avoid the families of missing people which further adds fuel to the fire.

The state of Jammu \& Kashmir has also a unique history, when the topic of human rights violation and enforced disappearances is touched. Since the inception of insurgency there have been thousands of disappearances in Kashmir. Therefore, the issue of disappearance in the state of Jammu \& Kashmir has become a topic of interest not only for the local social activitists and researchers but many international organizations such as Action Aid India and International Committee of Red Cross have been actively studying the status of the families of the disappeared persons. It has been commonly observed that to talk in the very language of rights with the families of disappeared person's remains an external discourse and means a little to them. The reason is that the vast majority of the families talk of the problems they face and the needs that emerge from those problems every day, and this becomes the natural language when discussing the issues arising from their victimhood (ICRC, 2009). A majority of families of disappeared persons report symptoms consistent with the impact of trauma and are disabled by mental illness. Many display chronic physical symptoms, presumably somatic, and attribute it to the long-term effect of the disappearance. A number of wives of missing persons face extreme stigmatization in their homes that has led to their being rejected by their in-laws, leaving voluntarily or continuing to live there in terrible conditions (Robins, 2006). Having a missing relative makes a family poorer. A minority of households faces challenges in feeding their families, and a small number of households with no economically active member have no alternative but to beg for food (Zia, 2009). Families articulate their economic needs in terms of what they cannot afford, and for most this prioritizes food, education and health care (Dabla, 2012). A study by Choudhury, Amreen; Moser; Puangsuwan \& Yeshua, (2007) reveal that majority of disappeared 


\section{Study of Mental Health Status of the Family Members of Disappeared Persons of Kashmir}

persons in Kashmir are males from poor families who lack knowledge of their legal rights. The disappeared are often the main or only income providers in their households, solely responsible for financially supporting wives, children, and frequently parents. Children of the disappeared have become half orphans, undergoing "high level of psychiatric problems. The trauma of losing a family member along with the added stress of shouldering family responsibilities played havoc with the delicate equilibrium of many adolescents” (Amnesty report, 1999). These hardships leave a deep negative impact on the mental health of these family members. The present study will be an attempt in this regard to study the status of mental health of the family members of disappeared persons with special focus on socio-demographic variables.

\section{Sample:}

The sample of the present study consisted family members of disappeared persons belonging to three districts namely, Srinagar, Anantnag and Baramulla of the Kashmir Valley. Regarding the actual figures of disappeared persons in Kashmir there were different opinions from both governmental as well as non-governmental fronts. The investigator approached the Association of Parents of Disappeared Persons (APDP) office and the organization provided a list consisting of 1248 registered disappeared persons belonging to different areas of Kashmir valley along with their residential addresses. From that list, the researcher sought out the areas from which maximum number of disappearances had occurred. Hence, three areas namely, Anantnag, Baramulla and Srinagar were selected for the purpose of data collection. The actual number of families of disappeared persons to be considered for the study was 134, 59 \& 201 from District Srinagar, Anantnag and Baramulla respectively. Finally 40(30\%), 18(30\%) and 51(25\%) families from Srinagar, Anantnag and Baramulla respectively were randomly selected as a sample group for the present study. From each family, two persons Mother and Father (in case the disappeared person was unmarried), Wife and Children (in case the disappeared person was married) were consulted for collecting the information. The respondents (family members) were contacted individually mostly by visiting to their houses. Thus the total number of families from all the three districts were 109 which comprised of 217 persons, of whom 89 (41.01\%) were males and 128 (58.99\%) were females. Out of 217 persons, 36 (16.59\%) belonged to District Anantnag [17 (47.22\%) males \& 19 (52.78\%) females]; 80 (36.87\%) belonged to District Srinagar [33 (41.25\%) males \& 47 (58.75\%) females] and, 101 (46.54\%) belonged to District Baramulla [38 (37.62\%) males \& 63 (62.38\%) females].

\section{Research Tools}

Mental Health Inventory by Davies A. R., Sherbourne C.D., Peterson, J.R., \& Ware, J. E. (1988). The scale consists of 38 items further divided in to six subscales, three of which are negative aspects of mental health (Anxiety, Depression and Loss of Behavioral and Emotional Control) while the three are positive aspects of mental health (General Positive Affect, Emotional Ties and Life Satisfaction) with their respective items that is, anxiety (3, 11, 13, 15, $25,29,32,33,35)$, depression $(9,19,30,36)$, loss of behavioral and emotional control $(8,14,16$, $18,20,21,24,27,28)$, general positive affect $(4,5,6,7,12,17,26,31,34,37)$, emotional ties 
$(10,23)$ and life satisfaction (1). The full-length version of the Mental Health Inventory has a Cronbach alpha of .93 while the short form has an alpha of .82. In the field testing for the Multiple Sclerosis Quality of Life Inventory the Mental Health Inventory showed good convergent and discriminant validity.

\section{Procedure of Data Collection:}

On the basis of information about the residences of the selected respondents of the study, the researcher approached them one by one. In order to grant the consent of the respondents, the need and purpose of the present study was explained to them under. After a brief introduction about the happenings of disappearances of their near ones, the schedules were used to get the required information from them. It was also assured to the respondents that all their information will be kept confidential and will be only used for the purpose of research.

\section{Statistical Measures:}

The responses collected from the respondents were subjected to various statistical measures by using Statistical Product and Service Solutions version 16.0 (SPSS 16.0). The main statistical techniques used for analyzing data were descriptive statistics (frequency distribution) and inferential statistics (t-test).

\section{RESULTS}

Table 1.1: Frequency distribution of Family Members of the Disappeared Persons with respect to negative Dimensions of their Mental Health (Anxiety, Depression \& Loss of Behavioral and Emotional Control) $\mathrm{N}=217$.

\begin{tabular}{|l|l|l|l|l|}
\hline $\begin{array}{l}\text { Negative Mental Health } \\
\text { Dimensions }\end{array}$ & Levels & Range & f & \%age \\
\hline \multirow{4}{*}{ Anxiety } & Low & $9-20$ & 0 & 0 \\
\cline { 2 - 5 } & Average & $21-42$ & 104 & 47.92 \\
\cline { 2 - 5 } & High & $43-54$ & 113 & 52.08 \\
\hline \multirow{4}{*}{\begin{tabular}{l} 
Depression \\
\multirow{3}{*}{$\begin{array}{l}\text { Loss of Beh. \& Emtrol } \\
\text { Cont. }\end{array}$}
\end{tabular}} & Low & $4-8$ & 4 & 1.84 \\
\cline { 2 - 5 } & Average & $9-17$ & 86 & 39.69 \\
\cline { 2 - 5 } & High & $18-22$ & 127 & 58.52 \\
\cline { 2 - 5 } & Low & $9-20$ & 1 & 0.46 \\
\cline { 2 - 5 } & Average & $21-42$ & 129 & 50.44 \\
\hline
\end{tabular}

The table 1.1 shows the levels of negative dimensions of mental health of family members of disappeared persons. As is evident from the table that out of the total sample (217), none (0\%); 4(1.84\%); and 1(0.46\%) have low level while as 113(52.08\%); 127(58.52\%); and 87(40.50\%) have high level of anxiety, Depression and Loss of Behavioral \& emotional Control respectively. 
Table1.2: Frequency distribution of Family Members of the Disappeared Persons with respect to positive Dimensions of their Mental Health (General Positive Affect, Emotional Ties, Life Satisfaction \& Overall Mental Health) $N=217$

\begin{tabular}{|l|l|l|l|l|}
\hline $\begin{array}{l}\text { Positive Mental Health } \\
\text { Dimensions }\end{array}$ & Levels & Range & f & \%age \\
\hline \multirow{3}{*}{ General Positive Affect } & Low & $10-22$ & 43 & 19.81 \\
\cline { 2 - 5 } & Average & $32-47$ & 29 & 13.36 \\
\cline { 2 - 5 } & High & $48-60$ & 145 & 66.83 \\
\hline \multirow{3}{*}{ Emotional Ties } & Low & $2-4$ & 44 & 20.27 \\
\cline { 2 - 5 } & Average & $5-8$ & 94 & 43.31 \\
\cline { 2 - 5 } & High & $9-12$ & 79 & 36.41 \\
\hline \multirow{3}{*}{ Life Satisfaction } & Low & $1-2$ & 170 & 78.34 \\
\cline { 2 - 5 } & Average & $3-4$ & 45 & 20.73 \\
\cline { 2 - 5 } & High & $5-6$ & 2 & 0.93 \\
\hline
\end{tabular}

The table 1.2 shows the levels of positive dimensions of mental health of family members of disappeared persons. From the table, it is evident that out of the total sample (217), 43(19.18\%); 44(20.27\%); 170(78.34\%) have low level while as 145(66.83\%); 79(36.41\%) and two (0.93\%) have high level of General Positive Affect, Emotional Ties and Life Satisfaction respectively. The table further indicates that $114(52.54 \%)$ have low level while as one (0.46\%) have high level of Over All Mental Health respectively.

Table 1.3: Comparison of Mean Scores of Negative Dimensions of Mental Health (Anxiety, Depression \& Loss of Behavioral and Emotional Control) of Family Members of the Disappeared Persons With Respect To their Family Type (N=217).

\begin{tabular}{|c|c|c|c|c|c|c|}
\hline $\begin{array}{l}\text { Negative Dimensions of } \\
\text { Mental Health }\end{array}$ & Group & $\mathbf{N}$ & $\mathbf{M}$ & SD & df & (t) \\
\hline \multirow{2}{*}{ Anxiety } & Nuclear & 141 & 46.53 & 5.13 & \multirow{2}{*}{215} & \multirow{2}{*}{$17.86^{*}$} \\
\hline & Joint & 76 & 33.28 & 5.14 & & \\
\hline \multirow{2}{*}{ Depression } & Nuclear & 141 & 19.14 & 3.02 & \multirow{2}{*}{215} & \multirow{2}{*}{$11.73^{*}$} \\
\hline & Joint & 76 & 13.94 & 3.69 & & \\
\hline \multirow{2}{*}{$\begin{array}{l}\text { Loss of Behavioral \& Emotional } \\
\text { Control }\end{array}$} & Nuclear & 141 & 42.99 & 6.74 & \multirow{2}{*}{215} & \multirow{2}{*}{$7.97 *$} \\
\hline & Joint & 76 & 35.48 & 6.34 & & \\
\hline
\end{tabular}

(*sig. $p \leq .05)$

Table 1.3 shows the $t$-values of the negative dimensions of mental health (Anxiety, Depression \& Loss of Behavioral and Emotional Control) of family members of disappeared persons on the basis their family type. From the table it is evident that t-values of all the three dimensions namely; Anxiety $(\mathbf{t = 1 7 . 8 6})$, Depression $(\mathbf{t}=\mathbf{1 1 . 7 3})$, Loss of behavioral and Emotional Control $(\mathbf{t}=7.97)$ are significant at .05 level of significance which indicates that nuclear and joint families of disappeared persons differ in mental health. 
Table 1.4: Comparison of Mean Scores of Positive Dimensions of Mental Health (General Positive Affect, Emotional Ties, Life Satisfaction \& Overall Mental Health) of Family Members of the Disappeared Persons With Respect To their Family Type (N=217).

\begin{tabular}{|c|c|c|c|c|c|c|}
\hline $\begin{array}{l}\text { Positive Dimensions of } \\
\text { Mental Health }\end{array}$ & Group & $\mathbf{N}$ & $\mathbf{M}$ & SD & df & (t) \\
\hline \multirow{3}{*}{$\begin{array}{l}\text { General } \\
\text { Positive Affect }\end{array}$} & Nuclear & 141 & 31.29 & 11.99 & \multirow{3}{*}{215} & \multirow{3}{*}{$5.45^{*}$} \\
\hline & & & & & & \\
\hline & Joint & 76 & 40.40 & 11.20 & & \\
\hline \multirow{2}{*}{ Emotional ties } & Nuclear & 141 & 4.46 & 2.48 & \multirow{2}{*}{215} & \multirow{2}{*}{$5.29 *$} \\
\hline & Joint & 76 & 6.35 & 2.56 & & \\
\hline \multirow{3}{*}{ Life Satisfaction } & Nuclear & 141 & 1.41 & .68 & \multirow{3}{*}{215} & \multirow{3}{*}{ 9.28* } \\
\hline & Joint & 76 & 2.47 & .97 & & \\
\hline & Joint & 76 & 114.36 & 31.69 & & \\
\hline
\end{tabular}

$\left({ }^{*}\right.$ sig. $\left.p \leq .05\right)$

Table 1.4 shows the $t$-values of the positive dimensions of mental health (General Positive Affect, Emotional Ties \& Life Satisfaction) of family members of disappeared persons with respect to their family type. It is evident from the table that t-value of all the positive dimensions of mental health namely, General Positive Affect $(\mathbf{t}=5.45)$, Emotional Ties (t=5.29), Life satisfaction (t=9.29) are significant at $(p \leq 05)$ level of significance. This indicates that those families of disappeared persons who live in nuclear families differ significantly in terms of their positive mental health dimensions as compared to those families who live in joint families.

Table 1.5: Comparison of Mean Scores of Negative Dimensions of Mental Health (Anxiety, Depression \& Loss of Behavioral and Emotional Control) of Family Members of Disappeared Persons With Respect To their Gender $(N=217)$.

\begin{tabular}{|c|c|c|c|c|c|c|}
\hline $\begin{array}{l}\text { Negative Dimensions of } \\
\text { Mental Health }\end{array}$ & Group & $\mathbf{N}$ & $\mathbf{M}$ & SD & df & (t) \\
\hline \multirow{2}{*}{ Anxiety } & Male & 89 & 40.41 & 8.64 & \multirow{2}{*}{215} & \multirow{2}{*}{$2.31^{*}$} \\
\hline & Female & 128 & 43.01 & 7.75 & & \\
\hline \multirow{2}{*}{ Depression } & Male & 89 & 17.55 & 4.47 & \multirow{2}{*}{215} & \multirow{2}{*}{$.00^{\mathrm{NS}}$} \\
\hline & Female & 128 & 17.55 & 3.987 & & \\
\hline \multirow{2}{*}{$\begin{array}{l}\text { Loss of Behavioral \& } \\
\text { Emotional Control }\end{array}$} & Male & 89 & 38.31 & 7.53 & \multirow[b]{2}{*}{215} & \multirow[b]{2}{*}{$3.41^{*}$} \\
\hline & Female & 128 & 41.79 & 7.24 & & \\
\hline
\end{tabular}

(*sig. $p \leq .05)$

Table 1.5 shows the $t$-values of the negative dimensions of mental health (Anxiety, Depression \& Loss of Behavioral and Emotional Control) of family members of disappeared persons on the 
basis their gender. It is evident from the Table that t-values of two of the three dimensions namely, Anxiety $(\mathbf{t}=\mathbf{2 . 3 1})$ and Loss of Behavioral \& Emotional Control $(\mathbf{t}=\mathbf{3 . 4 1})$ are significant at $p \geq .05$ level of significance. This indicates that male and female family members of the disappeared persons do not differ significantly in terms of Anxiety and Loss of Behavioral \& Emotional Control while as the $t$-value of Depression $(\mathbf{t}=\mathbf{. 0 0})$ is insignificant at $\mathbf{. 0 5}$ level of significance.

Table 1.6: Comparison of Mean Scores of Positive Dimensions of Mental Health (General Positive Affect, Emotional Ties \& Life Satisfaction) of Family Members of Disappeared Persons With Respect To their Gender (N=217).

\begin{tabular}{|c|c|c|c|c|c|c|}
\hline $\begin{array}{l}\text { Positive Dimensions of } \\
\text { Mental Health }\end{array}$ & Group & $\mathbf{N}$ & $\mathbf{M}$ & SD & df & (t) \\
\hline \multirow{3}{*}{ General Positive Affect } & Male & 89 & 37.28 & 10.05 & \multirow{3}{*}{215} & \multirow{3}{*}{$2.80 *$} \\
\hline & Гomolo & 120 & אר & 1237 & & \\
\hline & Female & 128 & 32.25 & 13.32 & & \\
\hline \multirow{2}{*}{ Emotional ties } & Male & 89 & 6.16 & 2.68 & \multirow{2}{*}{215} & \multirow{2}{*}{$5.10 *$} \\
\hline & Female & 128 & 4.38 & 2.43 & & \\
\hline \multirow{3}{*}{ Life Satisfaction } & Male & 89 & 1.88 & 1.10 & \multirow{3}{*}{215} & \multirow{3}{*}{$1.42^{\mathrm{NS}}$} \\
\hline & Female & 128 & 1.70 & .88 & & \\
\hline & Female & 128 & 85.96 & 35.69 & & \\
\hline
\end{tabular}

$\left({ }^{*}\right.$ sig. $\left.p \leq .05\right)$

Table 1.6 shows the $t$-values of the positive dimensions of mental health (General Positive Affect, Emotional Ties \& Life Satisfaction) of family members of disappeared persons with respect to their gender. The table shows that t-values of all the positive dimensions of mental health namely General Positive Affect $(\mathbf{t}=\mathbf{2 . 8 0})$ and Emotional Ties $(\mathbf{t}=\mathbf{5 . 1 0})$ are significant at .05 level of significance except Life Satisfaction $(\mathbf{t}=\mathbf{1 . 4 2})$. This indicates that there is a significant gender difference in positive dimensions of mental health among family members of disappeared persons.

Table 1.7:Comparison of Mean Scores of Negative Dimensions of Mental Health (Anxiety, Depression \& Loss of Behavioral and Emotional Control) of Family Members of Disappeared Persons With Respect to Age of the Disappeared Person at the time of his disappearance $(N=217)$.

\begin{tabular}{|c|c|c|c|c|c|c|}
\hline $\begin{array}{l}\text { Dimensions of Mental } \\
\text { Health }\end{array}$ & $\begin{array}{l}\text { Age of Disappeared } \\
\text { Person }\end{array}$ & $\mathbf{N}$ & $\mathbf{M}$ & SD & df & (t) \\
\hline \multirow{2}{*}{ Anxiety } & Up to 25 Years & 138 & 45.33 & 6.99 & \multirow{2}{*}{215} & \multirow{2}{*}{ 9.99* } \\
\hline & 25-50 Years & 79 & 35.81 & 6.66 & & \\
\hline \multirow{2}{*}{ Depression } & Up to 25 Years & 138 & 18.99 & 3.03 & \multirow{2}{*}{215} & \multirow{2}{*}{$7.84^{*}$} \\
\hline & 25-50 Years & 79 & 14.89 & 4.61 & & \\
\hline \multirow{2}{*}{$\begin{array}{l}\text { Loss of Behavioral \& } \\
\text { Emotional Control }\end{array}$} & Up to 25 Years & 138 & 41.93 & 6.99 & \multirow{2}{*}{215} & \multirow{2}{*}{$4.22 *$} \\
\hline & 25-50 Years & 79 & 37.62 & 7.63 & & \\
\hline
\end{tabular}

(*sig. $p \leq .05)$ 
Table 1.7 shows the $t$-values of the negative dimensions of mental health (Anxiety, Depression \& Loss of Behavioral and Emotional Control) of family members of disappeared persons with Respect to Age of the Disappeared Person at the time of his disappearance. From the table it is evident that t-values of these dimensions namely, Anxiety (t=9.99), Depression and (t=7.84), Loss of behavioral and Emotional Control $(\mathbf{t}=\mathbf{4 . 2 2})$ are significant at $(p \leq 05)$ level of significance. This indicates that those families whose family member disappeared in young age (25 years) differ significantly in terms of mental health dimensions namely, Anxiety, Depression and Loss of Behavioral \& Emotional Control, as compared to those families whose family member disappeared in middle or late adulthood (25-50 years).

Table 1.8: Comparison of Mean Scores of Positive Dimensions of Mental Health (General Positive Affect, Emotional Ties, Life Satisfaction \& Overall Mental Health) of Family Members of Disappeared Persons With Respect To Age of the Disappeared Person at the time of his disappearance $(N=217$

\begin{tabular}{|c|c|c|c|c|c|c|}
\hline $\begin{array}{l}\text { Positive Dimensions of } \\
\text { Mental Health }\end{array}$ & $\begin{array}{l}\text { Age of } \\
\text { Disappeared } \\
\text { Person }\end{array}$ & $\mathbf{N}$ & $\mathbf{M}$ & SD & df & (t) \\
\hline \multirow[t]{2}{*}{ General Positive Affect } & Up to 25 Years & 138 & 30.88 & 11.51 & \multirow[t]{2}{*}{215} & \multirow{2}{*}{ 6.06* } \\
\hline & 25-50 Years & 79 & 40.78 & 11.64 & & \\
\hline \multirow{2}{*}{ Emotional ties } & Up to 25 Years & 138 & 4.50 & 2.52 & \multirow{2}{*}{215} & \multirow{2}{*}{$4.72 *$} \\
\hline & 25-50 Years & 79 & 6.20 & 2.58 & & \\
\hline \multirow{2}{*}{ Life Satisfaction } & Up to 25 Years & 138 & 1.55 & .81 & \multirow{2}{*}{215} & \multirow{2}{*}{$5.18^{*}$} \\
\hline & 25-50 Years & 79 & 2.20 & 1.01 & & \\
\hline
\end{tabular}

$(*$ sig. $p \leq .05)$

Table 1.8 shows the t-values of the positive dimensions of mental health (General Positive Affect, Emotional Ties , Life Satisfaction \& Overall Mental Health) of family members of disappeared persons with Respect to Age of the Disappeared Person at the time of his disappearance. From the table it is evident that t-values of these dimensions namely, General Positive Affect $(\mathbf{t = 6 . 0 6 )}$, Emotional Ties $(\mathbf{t = 4 . 7 2})$, Life satisfaction $(\mathbf{t}=\mathbf{5 . 1 8})$ is significant at $\mathbf{0 5}$ level of significance which indicates that those families whose family member disappeared in young age (25 years) differ significantly in terms of mental health dimensions namely General Positive Affect, Emotional Ties, Life Satisfaction \& Overall Mental Health), as compared to those families whose family member disappeared in middle or late adulthood (25-50 years).

\section{DISCUSSION:}

The present study was aimed to assess the mental health status among the family members of the disappeared persons of Kashmir. The frequency method showed that of the total sample (217), (0\%); (1.84\%); and (0.46\%) have low while as (52.08\%); (58.52\%); and (40.50\%) have high level of anxiety, Depression and Loss of Behavioral \& emotional Control respectively. It was 


\section{Study of Mental Health Status of the Family Members of Disappeared Persons of Kashmir}

also found that of the total sample of ( $\mathrm{N}=217),(19.18 \%) ;(20.27 \%)$ and $(78.34 \%)$ have low while as (66.83\%); (36.41\%) and (0.93\%) have high General Positive Affect, Emotional Ties and Life Satisfaction respectively. A significant gender difference was found in dimensions of mental health of families of disappeared persons. Females scored high in anxiety and loss of behavioral and emotional control and low in life satisfaction, emotional ties and general positive affect. However, no significant difference was found in depression on the basis of gender. Study on parents of disappeared persons showed that females were found to have severe level of depression with more suicidal and sadness thoughts (Uzma \& Nazir, 2013). Similar results were found in a landmark study, which highlighted that majority of family members of disappeared persons especially women suffer from high level of psychological and physical problems including irritability, muscle tension, melancholy, aggressiveness, drug addiction, hyperactive vigilance, fallback, sleeplessness, nightmares, trauma and other emotional complications (Dabla, 2012). The results further showed that subjects whose family members were disappeared in their young age (25 years) scored high in negative dimensions of mental health namely, anxiety, depression and loss of behavioral and emotional control and low in general positive affect, emotional ties and life satisfaction as compared to those subjects whose family members were disappeared in late adulthood. The above results are in congruence with results of Goldberg, Breckenridge \& Sheikh (2003) who found that among younger adults 70\% scored higher in depression and anxiety while as only $60 \%$ of older adults scored higher in the same. Contrary to our results, Mackinnon, et. al. (1999) found a significant age difference in depression with older adults scoring higher and younger adults.

Respondents belonging to nuclear families scored high in negative dimensions of mental health (Anxiety, Depression, Loss of Behavioral \& Emotional Control) and low in positive dimensions of mental health (life satisfaction, emotional ties \& general positive affect) whereas respondents belonging to joint families scored high in positive dimensions of mental health (life satisfaction, emotional ties \& general positive affect) and low in negative dimensions of mental health (Anxiety, Depression, Loss of Behavioral \& Emotional Control). It can be inferred that nuclear families are susceptible to anxiety and depression as the disappeared family member might have been the sole earner of the family. It can also be said that in nuclear families as compared to joint families least amount of coping skills are available in the form of elders and other sources.

\section{REFERENCES:}

Amnesty International (1999). 'If they are dead, tell us' - "Disappearances" in Jammu and Kashmir, A Report. Retrieved from: www.amnesty.org/en/library/asset/... /002/1999. Choudhury, Amreen, Moser, Puangsuwan., \& Yeshua. (2007). Justice Disappeared: Exploring the links of Arms Trade, Impunity anp Political Disappearances. Non-violence International Southeast Asia. Retrieved from www.nonviolenceinternational.net/seasia Christensen, H., Jorm, A. F., Mackinnon, A. E., Jacomb, P. A., Rodgers, B., \& Henderson, A. S. (1999). Age differences in depression and anxiety symptoms: a structural equation 


\section{Study of Mental Health Status of the Family Members of Disappeared Persons of Kashmir}

modeling analysis of data from a general population sample. Psychological Medicine, 29(2): 325-339.

Dabla, B. A. (2012). Disappeared Persons and Conditions of their Families in Kashmir. News Update: Wednesday, November 28, 2012 Kashmir Times. www.kashmirtimes.com.

Daview, A. R., Sherbourne, C. D., Peterson, J. R., \& Ware. J. E. (1988). Scoring manual: Adult health status and patient satisfaction measures used in RAND'S Health Insurance Experiment. Santa Monica, CA: RAND Corporation.

Goldberg, G. H., Breckenridge, J. H. \& Sheikh, J. I. (2003). Age differences in symptoms of depression and anxiety: examining behavioral medicine outpatients. Journal of Behavioral Medicine. 26(2):119-132.

Hasanovic, M. Sinanovic, O., \& Pavlovic, S. (2002). Acculturation and psychological problems of adolescents from Bosnia and Herzegovina during exile and repatriation. Croat Med Journal, 46, 105-15.

Horowitz, M. (1997).Diagnostic criteria for complicated grief disorder. The American Journal of Psychiatry, July 1997. 154(7), 904-910.

Horowitz, M. (1997).Diagnostic criteria for complicated grief disorder. The American Journal of Psychiatry, July 1997. 154(7), 904-910.

Munczek, D. B. S., \& Tuber. S. (1998). Political repression and its psychological effects on Honduran children. Journal of Social Science and Medicine. 47, No. 11.

Rashid, U., \& Wani, N. A. (2013). The Level of Depression among Parents of Disappeared Children: a Quest of Some Psycho-Social Adjustment. International Journal of Innovative Research and Development, 2(6)236-254.

Zia, A. (2009). Women in Search for the Disappeared in Kashmir. Human Rights Fellowship Summer 2009. Department of Anthropology, UC Irvine. 